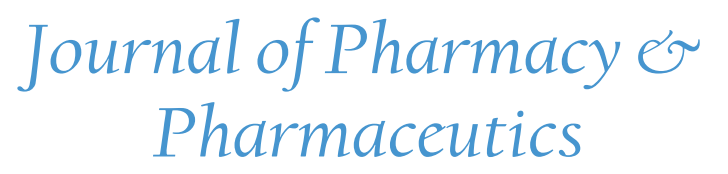

\title{
Simple and Sensitive Method for the Simultaneous Estimation of Drotaverine HCL and Aceclofenac Using RP-HPLC
}

\section{Selvadurai Muralidharan*}

Department of Pharmacy, Asian Institute of Medicine, AIMST University, Semeling, Bedong, 08100, Kedah, Malaysia

*Corresponding author: Selvadurai Muralidharan, Department of Pharmacy, Asian Institute of Medicine, Science and Technology (AIMST) University, Bedong-Semeling Road, Bedong, 08100, Kedah, Malaysia, Fax No: +6044298000; E-mail: murali23pharm@hotmail.com

\begin{abstract}
To develop a simple and sensitive method for the simultaneous estimation of drotaverine HCL (DRH) and aceclofenac (AF) using RP-HPLC. The HPLC separation was achieved on a thermo column $(250 \mathrm{~mm} \times 4.6 \mathrm{~mm}, 5 \mu)$ with an isocratic mixture of acetonitrile and $5 \mathrm{mM}$ of ammonium acetate in the ratio of $65: 35, \mathrm{pH}$ adjusted to 4.5 at a flow rate of $1.0 \mathrm{ml} / \mathrm{min}$ and the detection at $285 \mathrm{~nm}$. The method was validated as per ICH guidelines. The retention time for DRH and AF was 3.9 and 5.0 minutes, respectively. The optimized method was linear in the range of 50 - $120 \mathrm{ng} / \mathrm{ml}$ and $100-700 \mathrm{ng} / \mathrm{ml}$ for DRH and AF respectively. The overall recovery of DRH and AF were 99.8 and $99.5 \%$ respectively. The developed sensitive, robust and rugged method as proven reproducibility of the result obtained as an outcome of small deliberate variation in the analytical parameter and the change the operator.
\end{abstract}

Keywords: Aceclofenac; Drotaverine; Ddexibuprofen; Validation

Received date: May 14, 2014
Accepted date: May 20, 2014
Published date: May 23, 2014

Citation: Selvadurai M. Simple and Sensitive Method for the Simultaneous Estimation of Drotaverine HCL and Aceclofenac Using RP-HPLC (2014) J Pharma Sci Drug Des 1(1): 1- 3 .

DOI: $10.15436 / 2377-1313.14 .001$

\section{Introduction}

Drotaverine hydrochloride (DRH) is chemically known as 1-[(3; 4-[diethoxyphenyl) methylene]-6; 7diethoxy-1;2; 3; 4 tetrahydroisoquinolene hydrochloride ${ }^{[1]}$. Drotaverine hydrochloride is highly potent spasmolytic agent ${ }^{[2]}$. Aceclofenac $[\mathrm{AF}]$ is chemically designated as 2-(2; 6-Dichloroanalino) phenyl acetoxy acetic acid. It is a NSAID; used in the management of osteoarthritis; rheumatoid arthritis; and ankylosing spondylitis ${ }^{[3]}$. A few UV spectrophotometric andHPLC ${ }^{[4-7]}$ methods have been reported individually or in combination with other drugs for estimation of DRH. The aim of present study wasto propose a simple and sensitive method for quantification of DRHand AF to validate the procedures in order to demonstrate its good analytical and statistical parameters.

\section{Material and Methods}

\section{Materials}

The chromatographic separation was achieved on a Shimadzu high-pressure liquid chromatographic system equipped with a binary LC-20AD solvent delivery system; SPD-20A Photo Diode Array (PDA) detector and SIL-20ACHT injector with $50 \mu \mathrm{L}$ loop volume. The LC solution version 1.25 data acquisition system was used for data collecting and processing (Shimadzu Corporation; Japan). Thermo C18 (250 mm $\times 4.6 \mathrm{~mm}$ i.d.; $5.0 \mu)$ column was used for the analysis (Thermo scientific; USA). The HPLC grade of acetonitrile and ammonium acetate was obtained from Merck; Darmstadt; Germany. A molecular biology gradechemical of ammonium acetate was obtained from System Laboratory Chemicals and Reagents; Malaysia. Analytical grade of potassium dihydrogen phosphate was obtained from HmBG. 
Preparation of the calibration standards and quality control (QC) samples: The $1.0 \mathrm{mg} / \mathrm{ml}$ stock solutions of DRH and AF were prepared using mixture of water and methanol (1:1) solution. The working standards of DRH (at the concentration of 50; $60 ; 70 ; 80 ; 100$ and $120 \mathrm{ng} / \mathrm{ml})$ and $\operatorname{AF}(50 ; 60 ; 70 ; 80 ; 100$ and $120 \mathrm{ng} / \mathrm{ml}$ ) were prepared fromstock solution. The QC samples at three different levels viz.; 60; 80; $120 \mathrm{ng} / \mathrm{ml}$ and 200; 400 and $700 \mathrm{ng} / \mathrm{ml}$ were prepared and stored at $2-8^{\circ} \mathrm{C}$ until analyzed.

Sample preparation for analysis: Twenty tablets; each containing $80 \mathrm{mg}$ of DHR and $100 \mathrm{mg}$ of AF were weighed and finely powdered; aquantity of powder equivalent to $80 \mathrm{mg}$ and $100 \mathrm{mg}$ of combined dosageform were weighed and transferred to a sintered glass crucible. To this $5.0 \mathrm{ml}$ of $1.0 \mathrm{mg} / \mathrm{ml}$ solution of dexibuprofen (internal standard/IS) wasadded and the drugs were extracted with three quantities; each of $20 \mathrm{ml}$ of mixture of methanol and water $(1: 1 \mathrm{v} / \mathrm{v})$. The combined extracts were made up to $100 \mathrm{ml}$ with mobile phase and further dilutions were made and this solution was used for the estimation (Figure 1).

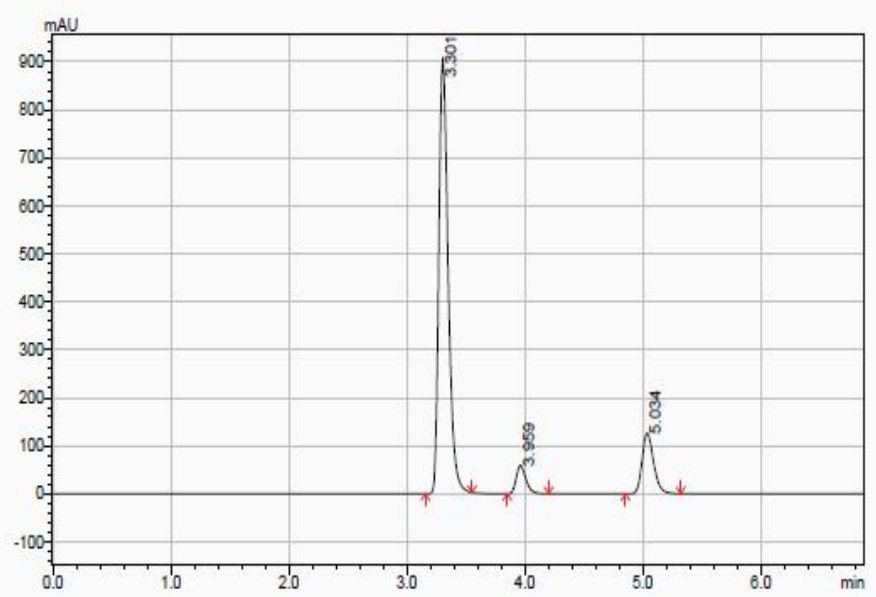

Figure 1: Typical standard chromatogram of drotaverine $\mathrm{HCl}$ and aceclofenac

Chromatographic conditions: Reverse phase RP-HPLC method was used for standardization of DRH and AF. The mobile phase used was acetonitrile and $5 \mathrm{mM}$ ammonium acetate $(\mathrm{pH}$ $4.5)$; in the ratio of $65: 35 \% \mathrm{v} / \mathrm{v}$. The mobile phase flow rate was maintained at $1 \mathrm{ml} / \mathrm{min}$ and the injection volume was $25 \mu \mathrm{l}$. The analytes was detected using PDA at $285 \mathrm{~nm}$.

\section{Validation}

The method was validated for linearity; precision; accuracy specificity; short-term stability; and system suitability ${ }^{[8]}$. Standard plots were constructed in the range of $50 ; 60 ; 70 ; 80$; 100 and $120 \mathrm{ng} / \mathrm{ml}$ of DHR and 100; 200; 300; 400; 500; 600 and $700 \mathrm{ng} / \mathrm{ml}$ of AF in triplicates to test linearity and it evaluated by linear regression analysis.

The precision of the assay was studied with respect to both repeatability and intermediate precision. Repeatability of the assay was assessed by six replicate injections of freshly prepared standard solution in same equipment on same day. Intermediate precision of the assay was assessed by assaying freshly prepared solution at the same concentration additionally on two consecutive days. Peak area ratio of standards to that of IS were determined and precision was reported as \% R.S.D.
Method accuracy was tested for its percentage recovery and percentage R.S.D. of individual measurements by analyzing samples of DHR and AF at three different levels in pure solutions using three preparations for each level. Specificity was assessed by comparing the chromatograms obtained from sample of pharmaceutical preparation and standard solution with those obtained from excipients which take part in the commercial tablets and verifying the absence of interferences. The short-term stability of the sample solution was tested at ambient temperature $\left(22 \pm 1^{\circ} \mathrm{C}\right)$ for three days. A system suitability test was performed by six replicate injections of the standard solution at a concentration to verifying IS/DI resolution $>2 ; \%$ R.S.D. of peak area ratios of drugs to that of IS $\pm 2 \%$; \% R.S.D. of each peak retention time $\pm 2 \%{ }^{[8,9]}$.

\section{Results and Discussion}

\section{Specificity}

The method specificity was assessed by comparing the chromatograms obtained from the drug with the most commonly used excipient mixture with those obtained from the blank solution. The blank solution was prepared by mixing the excipients in the mobile phase without the drug. The drug to excipient ration used was similar to that in the commercial formulations. The commonly used excipients in formulations like lactose; starch; microcrystalline cellulose; ethylcellulose; hydroxypropyl methylcellulose; magnesium stearate and colloidal silicon dioxide were used for the study. The mixtures were filtered through 0.45 $\mu$ membrane filter before injection. The recovery study is presented in Table 1.

Table 1: Results of analysis of formulation and recovery studies

\begin{tabular}{|l|l|c|l|l|}
\hline \multirow{2}{*}{ Drug (mg) } & \multicolumn{2}{|l|}{ Amount mg/ tablet } & $\begin{array}{l}\text { \% Label } \\
\text { claim* }\end{array}$ & $\begin{array}{l}\text { \% } \\
\text { Recovery* }\end{array}$ \\
\cline { 2 - 5 } & Labelled & Found * & \\
\hline $\begin{array}{l}\text { Drotaverine } \\
\text { HCL }\end{array}$ & 80.00 & $78.91 \pm 1.70$ & $99.01 \pm 1.01$ & $99.88 \pm 1.02$ \\
\hline Aceclofenac & 100.00 & $98.94 \pm 1.56$ & $99.25 \pm 1.21$ & $99.95 \pm 0.97$ \\
\hline
\end{tabular}

\section{Precision Studies}

Precision is the degree of repeatability of an analytical method under normal operational conditions. The precision of the method was studied in terms of repeatability (intra-day assay) and intermediate precision (inter-day assay). Method repeatability was studied by repeating the assay 3 times in the day for intra-day precision and intermediate precision was studied by repeating the assay on three different days; three times on each day (inter-day precision). The intraday and interday variation for determination of ceftazidime was carried out at 3 different concentrations levels. $\%$ RSD values were calculated (Table $2 \& 3)$. 
Table 2: Intraday and interday precision studies of Drotaverine $\mathrm{HCl}$

\begin{tabular}{|l|c|l|l|c|l|l|}
\hline \multirow{2}{*}{} & \multicolumn{3}{|c|}{ Intraday studies } & \multicolumn{3}{c|}{ Interday studies } \\
\cline { 2 - 7 } & $\begin{array}{l}\mathbf{6 0} \\
\mathbf{n g} / \mathbf{m l}\end{array}$ & $\begin{array}{l}\mathbf{8 0} \\
\mathbf{n g} / \mathbf{m l}\end{array}$ & $\begin{array}{l}\mathbf{1 2 0} \\
\mathbf{n g} / \mathbf{m l}\end{array}$ & $\begin{array}{l}\mathbf{6 0} \\
\mathbf{n g} / \mathbf{m l}\end{array}$ & $\begin{array}{l}\mathbf{8 0} \\
\mathbf{n g} / \mathbf{m l}\end{array}$ & $\begin{array}{l}\mathbf{1 2 0} \\
\mathbf{n g} / \mathbf{m l}\end{array}$ \\
\hline Mean & 58.95 & 79.03 & 119.14 & 59.12 & 79.66 & 119.61 \\
\hline SD & 0.500 & 0.86 & 0.50 & 0.30 & 0.41 & 0.37 \\
\hline \%CV & 0.85 & 1.08 & 0.42 & 0.51 & 0.51 & 0.31 \\
\hline \%Accuracy & 98.25 & 8.78 & 99.28 & 98.54 & 99.58 & 99.67 \\
\hline
\end{tabular}

Table 3: Intraday and interday precision studies of Aceclofenac

\begin{tabular}{|l|c|c|c|c|l|l|}
\hline \multirow{2}{*}{} & \multicolumn{3}{|c|}{ Intraday studies } & \multicolumn{3}{c|}{ Interday studies } \\
\cline { 2 - 7 } & $\begin{array}{l}\mathbf{6 0} \\
\mathbf{n g} / \mathbf{m l}\end{array}$ & $\begin{array}{l}\mathbf{8 0} \\
\mathbf{n g} / \mathbf{m l}\end{array}$ & $\begin{array}{l}\mathbf{1 2 0} \\
\mathbf{n g} / \mathbf{m l}\end{array}$ & $\begin{array}{l}\mathbf{6 0} \\
\mathbf{n g} / \mathbf{m l}\end{array}$ & $\begin{array}{l}\mathbf{8 0} \\
\mathbf{n g} / \mathbf{m l}\end{array}$ & $\begin{array}{l}\mathbf{1 2 0} \\
\mathbf{n g} / \mathbf{m l}\end{array}$ \\
\hline Mean & 198.75 & 398.73 & 699.10 & 198.71 & 398.99 & 699.58 \\
\hline SD & 0.30 & 0.37 & 0.25 & 0.33 & 0.40 & 0.29 \\
\hline \%CV & 0.15 & 0.09 & 0.03 & 0.16 & 0.10 & 0.04 \\
\hline \%Accuracy & 99.37 & 99.68 & 99.87 & 99.35 & 99.74 & 9.94 \\
\hline
\end{tabular}

\section{Accuracy}

Accuracy of the method was evaluated by standard addition method. An amount of the pure drug at 3 different concentration levels was added to the pre analyzed working standards solution of the drug. The sample solutions were analyzed in triplicate at each level as per the proposed method.

\section{Robustness}

The study was conducted to determine the effect of deliberate variations in the optimized chromatographic conditions like composition of the mobile phase; flow rate and $\mathrm{pH}$ of the mobile phase. The effect of these changes on the system suitability parameters like tailing factor and the number of theoretical plates and on assay was studied. A single condition was varied at a time keeping all other parameters constant like; variations in the composition of the mobile phase; variations in the $\mathrm{pH}$ of the mobile phase and variations in flow rate (evaluated at $1.4 \mathrm{ml} /$ $\min )$.

\section{Stability of the analytical solution}

A study to establish bench top stability was conducted. A freshly prepared working standard solution $(100 \mu \mathrm{g} / \mathrm{mL}$ of the drug) was analyzed immediately and at different time intervals. The tailing factor; theoretical plates and difference in percent assay at different time intervals were calculated.

\section{Limit of detection (LOD) and limit of quantification (LOQ)}

LOD is defined as the lowest concentration of analyte that gives a measurable response. It is determined based on signal to noise ratio $(\mathrm{S} / \mathrm{N})$ of three times typically for HPLC methods. LOQ is defined as the lowest concentration that can be quantified reliably with a specified level of accuracy and precision. It is the lowest concentration at which the precision expressed by a RSD less than $2 \%$.

\section{System precision and system suitability}

System precision and System suitability studies were carried out by injecting six replicates of the working standard (Table 4).
Table 4: System suitability studies

\begin{tabular}{|l|c|c|}
\hline Parameters & Drotaverine HCl & Aceclofenac \\
\hline Theoretical plate/meter & 4672 & 4589 \\
\hline Asymmetric factor & 0.93 & 0.91 \\
\hline LOD (ng/ml) & 30 & 50 \\
\hline LOQ (ng/ml) & 50 & 100 \\
\hline
\end{tabular}

\section{Conclusion}

The proposed RP-HPLC method is rapid; specific; accurate and precise for the quantification of DHR and AF from its tablet dosage form. The method has been found to be better than previously reported methods; because of its wide range of linearity; use of readily available mobile phase; lack of extraction procedures and low tR. All these factors make this method suitable for quantification of DHR \& AF in tablet dosage forms. The method can be successfully used for routine analysis of DHR and AF in quality control; bulk drugs and pharmaceutical dosage forms without interference.

\section{References}

1. Oneil M.J., Smith A., Heckelman P.E. The Merck Index, $13^{\text {th }}$ ed (2001) Merck, Whitehouse Station. New Jersey: 3489.

2. Chitlange S.S., Ranjana S., Wankhede S.B., Kulkarni AA. Spectrophotometric methods for simultaneous estimation of nimesulide and drotaverine (2009) Intern J Chem Tech Research 1: $135-138$.

3. The Merck index an encyclopedia of chemicals, Drugs, and biologicals $13^{\text {th }}$ ed. (2001) Merck Research Laboratories, Whitehouse station. New Jersey: 609-610.

4. Dahivelkar P.P., Surana S.J. Spectrophotometric method for simultaneous estimation of drotaverine hydrochloride and mefenamic acid in bulk and tablet formulation (2006) Indian Drugs 43: 896-900

5. Ayad M.M., Youssef N.F., Abdellatif H.E., Soliman S.M. A comparative study on various spectrometries with thin layer chromatography for simultaneous analysis of drotaverine and nifuroxazide in capsules (2006) Chem Pharm Bull 54: 807-813. 6. Panigrahi D., Sharma R. Development and validation of an RP-HPLC method for simultaneous analysis of drotaverine and omeprazole in a tablet dosage form (2008) J Acta Chromatographica 20: 439-450.

7. Momin M.Y., Yeole P.G., Puranik M.P., Wadher S.J. Reverse phase HPLC method for determination of aceclofenac and paracetamol in tablet dosage form (2006) Indian J Pharm Sci 68: 387-389.

8. ICH-Q2B. Validation of analytical procedures: Methodology (1996) International Conference on harmonization of technical requirements for registration of pharmaceuticals for human use, Geneva, Switzerland. 